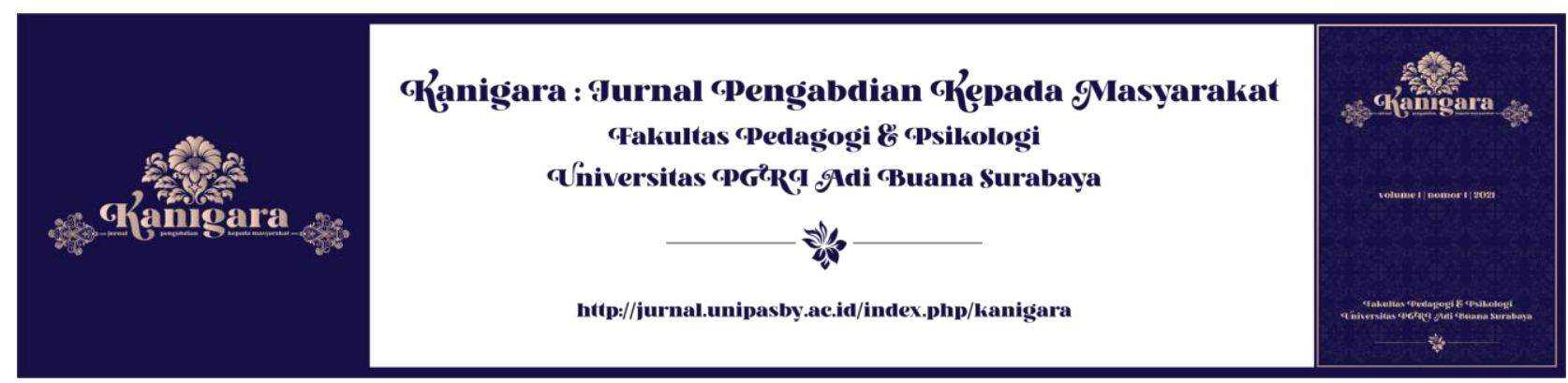

\title{
PEMBERDAYAAN MASYARAKAT DENGAN INOVASI “NDAWET KUY" (DAWET SIWALAN) PRODUK UMKM DESA DALEGAN GRESIK
}

\author{
Elia Firda Mufidah", Dini Atik Putri Anindya ${ }^{2}$, Nailatul Rifdah ${ }^{3}$, Ferry Rohman \\ Hakim ${ }^{4}$ \\ ${ }^{1}$ Bimbingan dan Konseling, Universitas PGRI Adi Buana Surabaya, Surabaya, Indonesia \\ *Email: eliafirda@unipasby.ac.id
}

\begin{tabular}{|c|c|}
\hline Informasi Artikel & Abstrak \\
\hline $\begin{array}{l}\text { Kata kunci: } \\
\text { pelatihan, } \\
\text { dawet siwalan, } \\
\text { dawet Kuy }\end{array}$ & $\begin{array}{l}\text { Dawet siwalan merupakan salah satu produk yang ada di pesisir } \\
\text { pantai Dalegan Gresi. Dawet siwalan memiliki kendala dalam hal } \\
\text { daya tarik pembeli yang masih rendah. Oleh sebab iitu peneliti } \\
\text { membuat pelatihan inovasi dawet siwalan dengan "Dawet Kuy". }\end{array}$ \\
\hline $\begin{array}{l}\text { Diterima: } 16-01-2021 \\
\text { Disetujui: 23-01-2021 } \\
\text { Dipubikasikan: } 25-01- \\
2021\end{array}$ & $\begin{array}{l}\text { Inovasi ini mengarah kepada inovasi dalam varian, tampilan dan } \\
\text { penggunaan digital marketing. Hasil pelatihan "Dawet Kuy" } \\
\text { diperoleh data bahwa peserta sangat antusias dan pelatihan ini } \\
\text { sangat bermanfaat untuk pengembangan usaha yang dimiliki oleh } \\
\text { para peserta. Peserta mampu dalam membuat olahan varian rasa } \\
\text { dawet siwalan dan tampilan packing yang lebih menarik serta } \\
\text { kemampaun memasarkan secara online dengan jangkauan } \\
\text { konsumen yang lebih luas. }\end{array}$ \\
\hline
\end{tabular}

Siwalan dawet is one of the products on the coast of Dalegan Gresi. Siwalan Dawet has problems in terms of low buyer attractiveness. Because of that, the researcher made dawet siwalan innovation training with "Dawet Kuy". This innovation leads to innovation in the variant, appearance and use of digital marketing. The results of the "Dawet Kuy" training showed that the participants were very enthusiastic and this training was very useful for the development of the businesses owned by the participants. Participants are able to make processed dawet siwalan flavors and a more attractive appearance of packing and the ability to market online with a wider reach of consumers. 


\section{PENDAHULUAN}

UMKM merupakan pelaku usaha dibidang ekonomi yang masuk dalam kategori perusahaan berskala kecil, menggunaakn cara atau teknologi yang tradisional dan pengelolahannya dengan sederhana (Laena, 2010). Menurut Azis dan Ruslan (2009), indicator dari sebuah UMKM yakni besar dan volume dari usahanya, besar modal yang dimiliki, nilai dari asset, penghasilan bersih, dan jumlah dari pekerja. UMKM menjadi hal penting yang ada di masyarakat. Keberadaannya membantu menyokong perputaran roda perekonomian yang ada di masyarakat. Banyak menfaat dari adanya UMKM diantaranya yakni pendestribusian pendaparan masyarakat, terciptanya lowongan pekerjaan, terasahnya kreatifitas masyarakat, menjadi instrument untuk mengukur daya beli masyarakat dan lain lain (Anggraeni, dkk., 2013). UMKM juga memiliki keunggulan dalam hal fleksibilutas dalam menyesuaikan kondisi pasar yang cukup cepat (Azrin, 2004)

Pemerintah sudah melakukan beberapa langkah untuk memberdayakan UMKM yang ada di Indonesia. UMKM sebagai produk khas masyarakat Indonesia tentunya keberadaannya sangatlah penting untuk mendukung perputaran roda perekonomian dan mengetaskan pengangguran. Beberapa kebijakan dari pemerintah yakni diadakannya pelatihan untuk UMKM, potongan dari pajak yang harus dibayarkan oleh pelaku usaha, dan lain-lain. Pelatihan UMKM saat ini diarahkan untuk menjawab tantangan era 4.0 dimana pemasaran kearah digital marketing, Hal tersebutu sesuai dengan penelitian dari Asosiasi Penyelenggara Jasa Internet Indonesia (APJII) penggunaan internet mengarah kepada aplikasi bisnis seperti kegiatan pemasaran, penjualan dan lain sebagainya. Data tersebut bisa digunakan untuk landasan dari UMKM mengarahkan pemasaran produknya kearah digital marketing.

Selain hal itu, mayoritas penduduk Indonesia merupakan generasi milenial yang penuh dengan inovasi. Oleh sebab itu, produk-produk UMKM memiliki tantangan bagaimana inovasi yang dikembangkan untuk menarik minat atau daya beli dari masyakarat khususnya generasi milenial. Penggunaan e-commerce membantu pemasaran produk dengan jangkauan yang lebih luar (Permana, 2016).

Dalegan, sebuah desa yang terletak dipesisir pantai Kabupaten Gresik memiliki beberapa UMKM menarik untuk dikembangkan. Sebagai salah satu objek wisata yang ada di kabupatan Gresik, Dalegan memiliki sumberdaya alam buah siwalan yang tidak ada di tempat lain. Pohon siwalan menghasilkan beberapa produk diantaranya kerajinan, minuman legen dan dawet siwalan. Pada bagian ini, peneliti mengembangkan inovasi atau pembaharuan dari packaging dan varian dawet siwalan sesuai dengan gaya dari generasi milenial saat ini. Dawet siwalan merupakan salah satu UMKM yang ada di desa Dalegan. 
Dawet ini terbuat dari potongan buah siwalan, santan dan gula aren.

Ada beberapa kendala yang dihadapi oleh kelompok usaha "Dawet Siwalan" yang ada di desa Dalegan. Ketertarikan dari masyarakat terhadap dawet ini masih rendah. Selain itu, masyarakat belum mampu untuk mengembangkan varian yang dimiliki dari produk dawet siwalan. Penggunaan social media pun masih belum ada untuk dawet siwalan. Oleh sebab itu, disini peneliti melakukan pelatihan untuk pembuatan inovasi “Dawet Kuy” yang mampu menjawab kendala dari kelompok usaha.

\section{METODE}

Pelaksanaan program ini dilakukan melalui beberapa tahapan yakni:

1. Tahap Perencanaan

Langkah yang dilakukan ditahapan ini yakni

a. Merumuskan tujuan dari kegiatan ini. Rumusan dari tujuan kegiata yakni inovasi produk dawet siwalan menjadi "Dawet Kuy" dan pemasaran melalui digital marketing.

b. Menganalisis permasalahan. Peneliti sudah melakukan analisis permasalahan berupa banyaknya kendala yang dihadapi oleh pelaku usaha salah satunya adalah daya beli masyarakat.

c. Merancang pelatihan pembuatan "Dawet Kuy" dan pemasaran digital marketing.

2. Tahap Sosialisasi

Sosialisasi dilakukan dengan mitra pertokoan Musyarofah Grup Wisata Pasir Putih Dalegan

3. Tahap Pelatihan

Tahapan ini dilakukan dengan memberikan konsep dari "Dawet Kuy" yang sesuai dengan trend dunia kuliner saat ini terutama untuk minuman. Inovasi dalam pengolahan rasa dan kepraktisan tampilan menjadi salah satu pokok dari pelatihan ini. Selain itu, pengenalan social media maupun e-commerce untuk mendukung jangkauan pemasaran dari produk ini.

Berikut skema dari pelaksanaan pelatihan "Dawet Kuy": 


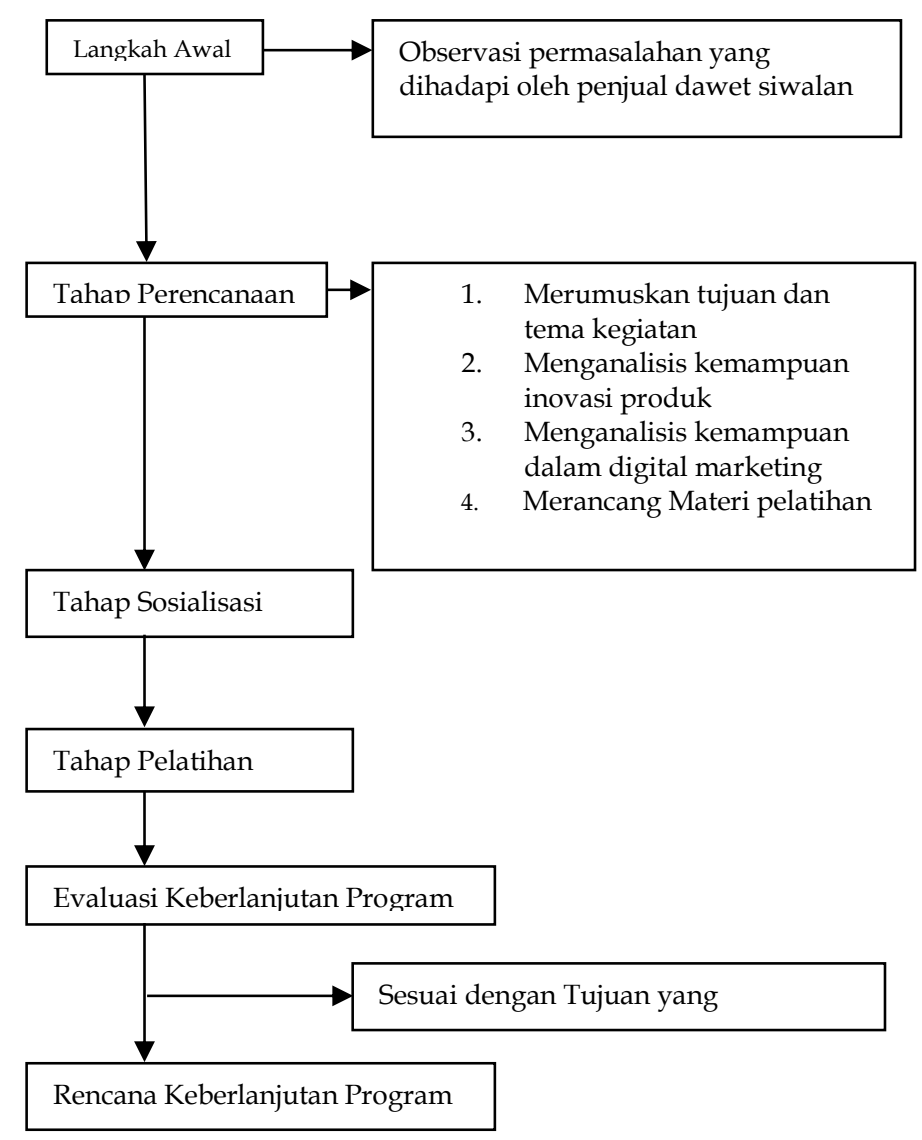

\section{HASIL DAN PEMBAHASAN}

Pelatihan ini dilakukan oleh mahasiswa KKN Universitas PGRI Adi Buana Surabaya Kelompok DPL 11 yang berlokasi di Kabupaten Gresik. Langkah awal dari pelatihan yang dibuat yakni melakukan analisis kebutujan penjualan dawet siwalan yang ada di pesisir pantai Dalegan Gresi. Dari hasil analisis kebutuhan diperoleh hasil yakni kebutuhan akan inovasi dari produk dawet siwalah agar daya beli dari masyarakat terutama generasi milenial menjadi meningkat. Terlihat di lokasi pesisir, kebanyakan pengunjung yang dating yakni generasi milenial. Selain itu, jangkauan pemasaran dawet siwalan juga membutuhkan strategi digital marketing agar mampu untuk memperluas jangkauan konsumen. Analisis kebutuhan ini diambil dengan cawa mewawancarai beberapa penjual yang ada di pantai Dalegan.

Setelah tahapan analisis kebutuhan, maka dilanjutkan untuk memutuskan bagaimana tema dari kegiatan pelatihan. Pelatiha ini bertemakan pembuatan "Dawet Kuy" dimana dawet siwalan akan memiliki inovasi varian dan pemasaran melalui digital marketing. Tahapan selanjutnya yakni tahapan sosialisasi dimana sosialisasi dilakukan melalui pengumpulan penjual dawet siwalan di balai pantai Dalegan sesuai dengan protokoler kesehatan. Sosialisasi diberikan dengan memaparkan konsep dari "Dawet Kuy". Terlihat 
antusias dari peserta dimana peserta yang datang lebih dari 10 dan keaktifan peserta untuk bertanya jawab dengan tim sosialisasi.

Tahap pelatihan yakni tahap pembuatan "Dawet Kuy". Kelompok usaha atau penjual dawet siwalan dikenalkan dengan varian rasa yang menjadi trend minuman kekinian generasi milenial, mulai dari perpaduan dengan rasa kopi, coklat, ovomaltine, greentea, vanilla, stroberi dan lain sebagainya. Selain itu dawet siwalan juga dikombinasikan dengan boba yang digemari oleh generasi milenial sebagai minuman kekinian mereka. Packing dari dawet siwalan juga sudah berubah dari yang biasanya menggunakan kantong plastic dengan sedotan diarahkan menggunakan gelas platik yang memiliki cup untuk tambahan topping. Inovasi-inovasi tersebut dilakukan dengan mempertimbangkan perhitungan HPP (Harga Pokok Penjualan) sehingga ketika pelatihan inovasi diberikan juga diselipkan bagaimana menghitung HPP.

Setelah dilakukan pelatihan inovasi dalam tampilan dawet siwalan. Selanjutnya yakni pengenalan digital marketing. Focus penggunaan digital marketing disini pada penggunaan jasa platform shoppe, facebook dan tokopedia. Penjualan melalui platform ini memfokuskan kepada penjualan siwalan frozen dengan mempertimbangkan bagaimana ketahanan pengiriman siwalan sehingga sampai kepada konsumen dengan baik. Platform ini masuk dalam dunia e-commercer dimana proses atau system didalamnya sudah terintegrasi secara utuh mulai dari e-process, e-market, e-communities, e-service, dan e-content (Julisar dan Eka, 2013). Peserta juga dikenalkan bagaimana membuka cabang jika mengembangkan penjualan frenchise.

Tahap evaluasi dari kegiatan pelatihan ini meliputi beberapa hal yang ditanyakan langsung kepada peserta pelatihan yang berjumlah sebanyak 10 orang. Semua peserta mengungkapkan ucapan berterimakasih dan mengungkapkan kegiatan pelatihan sangat bermanfaat untuk mereka. Berikut kami lampirkan foto kegiatan dan produk

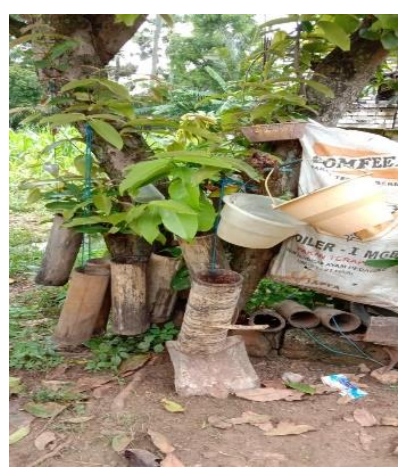

Gambar 1. Pohon siwalan 

Gresik

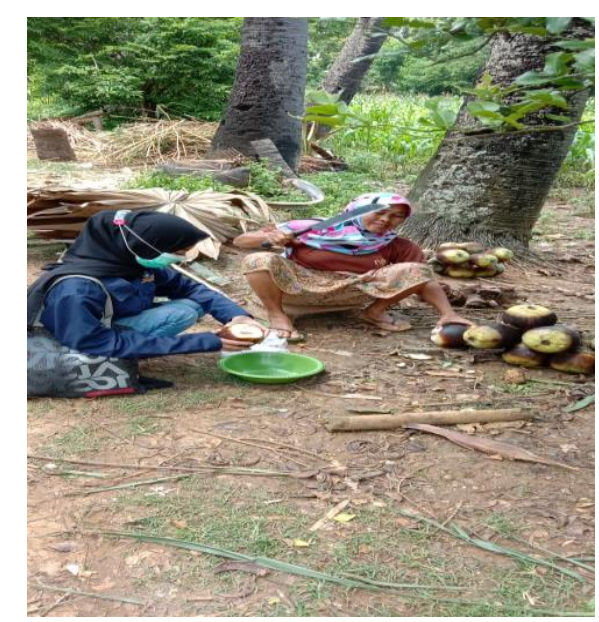

Gambar 2. Pengambilan buah siwalan

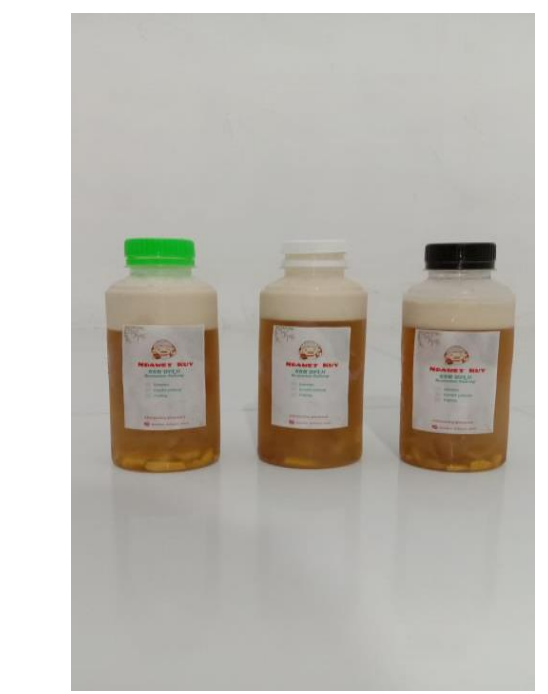

Gambar 3. Produk olahan dawet siwalan

\section{KESIMPULAN}

Kegiatan pelatihan pembuatan "Dawet Kuy" merupakan inovasi produk dawet siwalan dengan varian rasa yang banyak dan mengarah kepada pemahaman terkait digital marketing para penjual dawet siwalan di daerah pantai Dalegan. Hal ini diperlukan untuk mendukung berkembangnya UMKM sesuai dengan tuntutan era saat ini. Kebermanfaatan dari pelatihan ini sangat dirasakan oleh pelaku usaha dalam mengembangkan usaha yang mereka miliki. 


\section{DAFTAR PUSTAKA}

Anggraeni, F., D., dkk. 2013. Pengembangan Usaha Mikro, Kecil, dan Menengan (UMKM) Melalui Fasilitasi Pihal Eksternal dan Potensial Internal (Studi Kasus pada Kelompok Usaha “Emping Jagung" di Kelurahan Pndanwangi Kecamatan Blimbing, Kota Malang). Jurnal Adminstrasi Publik (JAP). 1 (6), 1286-1295

Azis, A dan Rusland, A.H. 2009. Pernanan Bank Indonesia dalam Mendukung Pengembangan Usaha Mikro, Kecil, dan Menengah. Jakarta: Pusat Pendidikan dan Studi Kebanksentralan (PPSK) Bank Indonesia

Azrin, M. 2004. Dampak Ekonomi Pengembangan Usaha Kecil dan Menengah Sektor perdagangan terhadap Perekonomian Kota Bogor.Tesis tidak dipublikasikan.Sekolah Pasca Sarjana Institut Pertanian Bogor (IPB). Bogor

Julisar\&Miranda Eka, 2013. Pemakaian E-Commerce untuk Usaha Kecil dan Menengah Guna Meningkatkan Daya Saing. Jakarta:Binus University.

Laena, I. 2010. Membedah UMKM Indonesia: Sebuah Kajian Tentang Strategi Pemberdayaan \& Pengmebangan Usaha Mikro Kecil Menengah di Indonesia, Jakarta: Lugas Foundation.

Permana, S.H. 2016. Peningkatan Peran Teknologi Informasi Dalam Pemasaran Produk UMKM di Indonesia, dalam buku bunga rampai yang berjudul Reformulasi Kebijakan Sektoral Ekonomi Indonesia Dalam Perspektif Globalisasi, Jakarta: Badan Keahlian DPR RI bekerjasama dengan Balai Pustaka. 